\title{
Evaluación de lodos de PTAR municipales como inóculos en la digestión anaerobia de biorresiduos
}

\section{Evaluation of sewage sludge from municipal WWTP as inoculum in the anaerobic digestion of biowaste}

\section{Avaliação de lodos de ETE municipais como inóculo na digestão anaeróbia fracção orgânica dos resíduos sólidos urbanos}

\author{
Brayan Alexis Parra Orobio ${ }^{1 *}$; Patricia Torres Lozada1; Luis Fernando Marmolejo Rebellón'; Wilmar \\ Alexander Torres López²; Lina Fuentes López¹; María del Mar Ossa Arias'; Luz Edith Barba Ho¹ \\ ${ }^{1}$ Escuela EIDENAR, ${ }^{2}$ Escuela de Estadística, Universidad del Valle, Calle 13 \# 100-00, Cali, Colombia. \\ *brayan.parra@correounivalle.edu.co
}

\begin{abstract}
Resumen
La cantidad y calidad del inóculo empleado en los procesos de Digestión Anaerobia (DA), incide significativamente sobre la biodegradabilidad y la cantidad de metano que se produce. Esta investigación evaluó el efecto de la procedencia de inóculos de plantas de tratamiento de aguas residuales municipales (PTAR) sobre la producción de metano como una fuente de energía renovable, a partir de la DA de Biorresiduos de Origen Municipal (BOM), analizando como aspectos claves la relación Sustrato-Inóculo (S/I) y la capacidad buffer del inóculo. Los experimentos se realizaron a escala de laboratorio mediante ensayos de Potencial Bioquímico de Metano (PBM) en el rango mesofílico con un Tiempo de Retención de Sólidos (TRS) de 21 días; dos de los inóculos procedieron de reactores UASB y el otro de un digestor anaerobio de lodos. Las relaciones $\mathrm{S} / \mathrm{l}$ oscilaron entre 0,5 y $12 \mathrm{gSV}_{\text {sustrato }} \mathrm{gSV}^{-1}{ }_{\text {inóculo }}$. Aunque se encontró que no existen diferencias estadísticas significativas entre los inóculos $(p>0,05)$, el inóculo procedente del digestor anaerobio presentó un mejor desempeño debido a su mayor capacidad buffer. La relación S/I presentó diferencias estadísticas significativas $(p<0,05)$, siendo las relaciones inferiores a 1 las que presentaron las mejores producciones de metano $\left(>70 \mathrm{mLCH}_{4} \mathrm{gSV}^{-1}{ }_{\text {sustrato }}\right)$, tasas de hidrólisis $\left(0,15-0,21 \mathrm{~d}^{-1}\right)$ $y$ fases de latencia $(2,7-9,3 d)$.
\end{abstract}

Palabras clave: biorresiduos, energía renovable, hidrólisis, lodos anaerobios, metano, relación sustrato-inóculo.

\begin{abstract}
The quantity and quality of inoculum used in the Anaerobic Digestion (AD), impact seriously on the biodegradability and the amount of methane produced. This research evaluated the effect of the source of inoculum municipal wastewater treatment plant (WWTP) on the production of methane as a source of renewable energy $A D$ from Municipal Biowaste (MB), analyzing the Substrate-Inoculum (S/I) ratio and the buffering capacity of the inoculum as key aspects. The experiments were performed on a laboratory scale by testing Biochemical Methane Potential (BMP) in the mesophilic range with a retention time of solids (RTS) 21 days; two inoculums from UASB reactors and the other of an anaerobic sludge digester. The $\mathrm{S} / \mathrm{I}$ ratios ranged between 0.5 and $12 \mathrm{gVS}_{\text {substrate }} \mathrm{gVS}^{-1}{ }_{\text {inoculum }}$. Although it was found that there were no statistically significant differences between the inoculum $(p>0.05)$, the inoculum from the anaerobic digester presented a better performance because of its greater capacity buffer. The $\mathrm{S} / \mathrm{l}$ ratio showed statistically significant differences $(p<0,05)$, being below 1 ratio that presented the best productions of methane $\left(>70 \mathrm{mLCH}_{4} \mathrm{gVS}^{-1}{ }_{\text {substrate }}\right.$ ) hydrolysis rates (from 0,15 to $0,21 \mathrm{~d}^{-1}$ ) and phases of lethargy $(2,7-9,3 d)$.
\end{abstract}

Cita: Parra Orobio BA, Torres Lozada P, Marmolejo Rebellón LF, Torres López WA, Fuentes López L, Ossa Arias MM, Barba Ho LE. Evaluación de lodos de PTAR municipales como inóculos en la digestión anaerobia de biorresiduos. rev.ion. 2016;29(1):37-46. 
Keywords: biowaste; renewable energy, hydrolysis, anaerobic sludge, methane, substrate-inoculum ratio.

\section{Resumo}

A quantidade e qualidade do inoculo utilizada na Digestão Anaerobia (DA), um impacto significativo sobre a biodegradabilidade e a quantidade de metano produzido. Esta pesquisa avaliou o efeito da fonte de inóculo de estações de tratamento, águas residuais municipais (ETARM) na produção de metano como fonte de energia renovável, a partir de DA resíduos biológicos de origem municipal (RBOM), analisando como aspectos importantes a relação substrato-inóculo (S/l), a capacidade buffer do inoculo. Os experimentos foram realizados em escala laboratorial por testes bioquímicos metano (BMP) na gama mesofílica com um tempo de retenção dos sólidos (TRS) de 21 dias; Dois inóculos foram de reatores UASB e outra de um digestor de lodo anaeróbio. O S/I a relação variou entre 0,5 e $12 \mathrm{gSV}_{\text {substrato }} \mathrm{gSV}^{-1}$ inoculo ${ }^{\circ}$ Embora verificou-se que não houve diferenças estatisticamente significativas entre o inóculo $(p>0,05)$, o inóculo do digestor anaeróbico apresentou um desempenho melhor por causa de seu buffer de maior capacidade. A relação $S / /$ mostrou diferenças estatisticamente significativa $(p<0,05)$, sendo as relações menores a 1 que apresentaram as melhores produções de metano $\left(>70 \mathrm{mLCH}_{4} \mathrm{gSV}^{-1}{ }_{\text {substrato }}\right)$ taxas de hidrólise (de 0,15 a $\left.0,21 d^{-1}\right)$ e fases de letargia $(2,7-9,3 d)$.

Palabras-chave: resíduos biológicos, energía renovável, hidrólise, lodo anaeróbio, metano, relação substratoinoculo.

\section{Introducción}

Los Biorresiduos de Origen Municipal (BOM) constituyen la fracción predominante en los Residuos Sólidos Municipales (RSM), donde en países desarrollados esta proporción puede llegar al $40 \%$ mientras que en los países en desarrollo oscila entre el 50 y $60 \%$. Los BOM se caracterizan por presentar propiedades fisicoquímicas con un alto potencial contaminante [1]; estas particularidades los hacen potencialmente aprovechables para la producción de energía renovable en forma de metano a partir de procesos de Digestión Anaerobia (DA). Al mismo tiempo, esta opción tecnológica presenta un claro aporte al control de contaminación que generan estos residuos.

Las pruebas de biodegradabilidad anaerobia como el Potencial Bioquímico de Metano (PBM), permiten evaluar la susceptibilidad de los Biorresiduos de Origen Municipal (BOM) de ser sometidos a este proceso y evaluar aspectos de importancia como la tasa de hidrólisis, fase de latencia, posibles efectos inhibitorios y las máximas eficiencias de transformación esperadas durante la transformación de los BOM [2].

Para garantizar la estabilidad del proceso de DA de BOM, se deben tener en cuenta factores asociados, entre otros, a condiciones ambientales $(\mathrm{pH}$, temperatura, concentración de nutrientes en el medio, entre otros) y la relación Sustrato-Inóculo (S/I); adicionalmente, la cantidad y calidad del inóculo es un factor que puede variar por su origen y la adaptación de las bacterias al sustrato a degradar [3]. Por consiguiente, la normalización de los ensayos PBM es compleja, puesto que es necesario obtener resultados confiables, reproducibles y universales.

Una de las metodologías más utilizadas para la determinación de PBM en BOM es la sugerida por Angelidaki et al. [4], en el cual se enfatiza en que el inóculo debe estar fresco, homogéneo y aclimatado. Así mismo, éste debe tener una diversidad microbiana para asegurar un nivel suficiente de actividad hidrolítica y metanogénica; sin embargo, en general la calidad del inóculo se determina a través de la determinación de los sólidos volátiles (SV), la cual no hace diferencia entre microorganismos vivos y muertos presentes en el inóculo, lo que puede generar errores en la identificación de la cantidad real de biomasa activa empleada en la prueba [5].

Estudios como el de Raposo et al. [3] señalan que la influencia del inóculo está relacionada con factores como el origen, la concentración, la Actividad Metanogénica Específica (AME), la pre-incubación, la aclimatación, adaptación y condiciones de almacenamiento. De Vrieze et al. [6] enfatizaron en que el principal tema a abordar sobre la influencia del inóculo son las poblaciones microbianas metanogénicas.

Un aspecto muy importante en la DA es la capacidad buffer en el proceso; sin embargo, esta característica fisicoquímica ha sido poco considerada en términos de la caracterización del inóculo. Por lo anterior, en este trabajo se evaluó mediante ensayos de Potencial Bioquímico de Metano (PBM) la producción de metano a partir de la Digestión Anaerobia (DA) de BOM utilizando inóculos provenientes de tres Plantas de Tratamiento de Agua Residual Municipales 
(PTARM), analizando como aspectos claves en el estudio la influencia de la relación $S / l$ y de la capacidad buffer del inóculo.

Materiales y Métodos

\section{Caracterización de sustrato e inóculos}

El sustrato (BOM) procedió de un restaurante universitario que atiende a más de 3000 estudiantes al día y genera $2,4 \mathrm{t} /$ semana, los cuales estaban constituidos en un $37 \%$ por carbohidratos (cáscaras de plátano, papa, entre otros), $31 \%$ por fibra y mezcla de minerales (cáscaras de huevo, apio, hierbas, entre otros), $14,5 \%$ por frutas no cítricas y $9 \%$ por frutas cítricas y semicítricas, respectivamente. Éstos fueron caracterizados de acuerdo a ICONTEC [7] y APHA [8] en términos de Humedad (\%), pH (UND), Alcalinidad total (AT) y bicarbonática $(\mathrm{AB})\left(\mathrm{mgCaCO}_{3} \mathrm{~L}^{-1}\right)$, Ácidos grasos volátiles (AGV's) $\left(\mathrm{mgL}^{-1}\right)$, Demanda Química de Oxígeno $\left(\mathrm{DQO}_{\text {total }} ; \mathrm{DQO}_{\text {filtrada }}\right)\left(\mathrm{mgO}_{2} \mathrm{~L}^{-1}\right)$, Demanda Bioquímica de Oxígeno $\left(\mathrm{DBO}_{5}\right)\left(\mathrm{mgO}_{2} \mathrm{~L}^{-1}\right)$, Sólidos totales (ST) y volátiles (SV) $\left(\mathrm{mgL}^{-1}\right), \mathrm{UV}_{254}\left(\mathrm{~cm}^{-1}\right)$, Carbono orgánico total, (COT) $\left(\mathrm{mgkg}^{-1}\right)$, Nitrógeno total $\left(\mathrm{mgkg}^{-1}\right)$, Nitrógeno amoniacal total $\left(\mathrm{mgL}^{-1}\right)$, Nitrógeno amoniacal total no ionizado e ionizado $\left(\mathrm{mgL}^{-1}\right)$ y Fósforo total $\left(\mathrm{mgkg}^{-1}\right)$.

Teniendo en cuenta que uno de los inóculos con mayor disponibilidad en el país son los lodos anaerobios procedentes de plantas de tratamiento de aguas residuales municipales (PTAR), se evaluaron los de dos reactores UASB que tratan aguas residuales de localidades con menos de 30000 habitantes (denominados Inóculos A y B) y los de un digestor anaerobio de lodos de una PTAR que utiliza Tratamiento Primario Avanzado (TPA) con $\mathrm{FeCl}_{3}$ (Inóculo C). Las tres localidades presentan sistemas de alcantarillado combinado. A los tres inóculos se les realizó la caracterización fisicoquímica en términos de $\mathrm{pH}, \mathrm{AT}, \mathrm{AB}, \mathrm{AGV}$ 's, ST, $\mathrm{SV}$, sedimentabilidad y AME $\left(\mathrm{gDQO} \mathrm{gSV}^{-1} \mathrm{~d}^{-1}\right)[9]$.

\section{Ensayos de PBM}

Previamente al ensayo de PBM, los BOM fueron sometidos a un proceso de trituración según lo recomendado por Sharma et al. [10], empleando una trituradora CB15 Waring Commercial a una velocidad de $15800 \mathrm{rpm}$ durante un minuto (velocidad estándar del equipo), garantizando tamaños de partículas inferiores a $30 \mathrm{~mm}$.

La cuantificación de biogás se realizó mediante el método manométrico, empleando el Sistema Oxitop ${ }^{\circ}$ el cual es un equipo de monitoreo de presión que consta de un reactor de $250 \mathrm{~mL}$ con un cabezal de medición que se inserta en la "boca" de los reactores y un control que usa una interfase infrarroja para transferir los datos [11]. Los ensayos se realizaron a temperatura controlada $\left(35^{\circ} \mathrm{C} \pm\right.$ $0,5^{\circ} \mathrm{C}$ ) en una incubadora WTW TS $606-\mathrm{G} / 2-\mathrm{i}$, con agitación manual intermitente durante 21 días, realizando mediciones cada 3 horas [12]. El volumen útil empleado fue de $200 \mathrm{~mL}$, dejando un espacio libre de $50 \mathrm{~mL}$ para el almacenamiento del biogás que se produce.

Para mantener condiciones estables en los ensayos PBM, se empleó una solución de macro y micronutrientes que parte del principio de que la técnica PBM busca garantizar las condiciones más favorables que potencialicen la degradación anaerobia del sustrato. La solución usada fue la sugerida por Angelidaki et al. [4]. Igualmente, se acondicionó el pH a 7,0 UND con una solución de $\mathrm{NaHCO}_{3}$ al $4 \%$. Para garantizar que la medición manométrica correspondiera predominantemente a metano, se capturó el dióxido de carbono a través de perlas de $\mathrm{NaOH}$ [13], la composición de metano fue verificada mediante el uso del Cromatógrafo GC2014 Shimadzu (para cuantificar el $\mathrm{CH}_{4}$ se usó un detector de ionización de llama (FID) y uno de captura de electrones (ECD); Precolumna y columna Porapak Q (80-100mesh); mientras para el $\mathrm{CO}_{2}$ se empleó un analizador infrarrojo con trampa de $\mathrm{NaOH}$ y sílica gel). Para determinar el volumen de metano a condiciones estándar-CE, se aplicaron las ecuaciones sugeridas por Parra et al. [14], en las que se considera la proporción de metano disuelto.

Para obtener diferentes valores de la relación $\mathrm{S} / \mathrm{l}$ en términos de $\mathrm{gSV}_{\text {sustrato }} \mathrm{gSV}^{-1}{ }_{\text {inóculo, }}$ en todas las unidades experimentales se mantuvo fija la concentración del inóculo, la cual correspondió a $1,5 \mathrm{gSV}_{\text {inóculo }} \mathrm{L}^{-1}$, valor recomendado para ensayos PBM sin agitación continua [15]. La concentración del sustrato fue modificada en términos de $\mathrm{gSV}_{\text {sustrato }}$ en cada unidad experimental. La Figura 1 muestra el esquema de las relaciones que se evaluaron. Cada una unidad experimental contó con su respectivo 


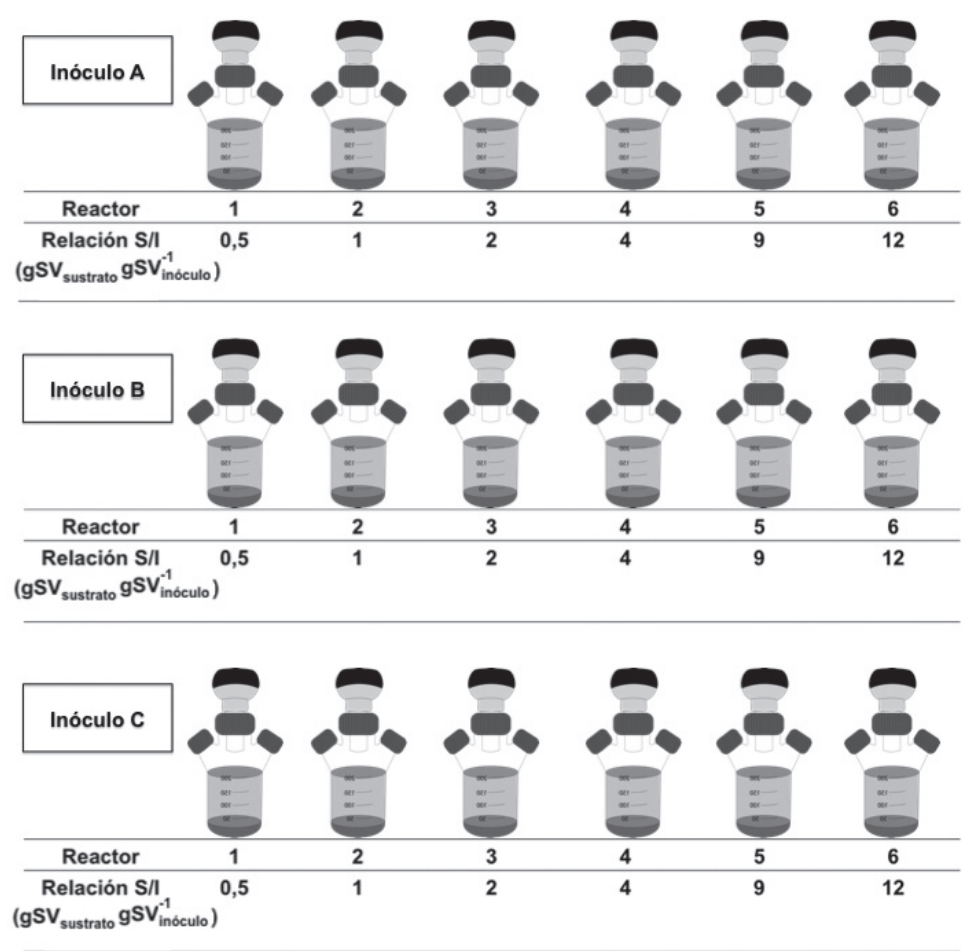

Figura 1. Esquema de la unidad experimental.

duplicado $(n=2)$ y con un control (inóculo más agua destilada) para realizar la corrección por el metano endógeno.

\section{Procesamiento estadístico}

Para determinar el efecto del inóculo y la relación S/l sobre el PBM, se aplicó un análisis de varianza (ANOVA) y una Prueba de Tukey con $p<0,05$, donde la variable respuesta fue el PBM mediante el paquete estadístico $\mathrm{R}$ i386 3.0.2.

\section{Análisis cinético}

La constante de hidrólisis $\left(k_{h}\right)$ se determinó aplicando un modelo cinético de primer orden de acuerdo a lo sugerido por Liew et al. [16]. Para ello se efectuó una linealización de los resultados de producción de metano obtenidos durante el tiempo que se realizó cada ensayo mediante las Ecuaciones 1 y 2. La primera permite convertir los datos obtenidos de presión en concentración (molL-1); mientras que la segunda sirve para determinar la constante de hidrólisis.

$$
M(t)=\frac{P}{R T}
$$

Donde $M(t)$ es la concentración de metano en un tiempo $t\left(\mathrm{molL}^{-1}\right)$; $P$ es la presión registrada por el
OXITOP $®($ atm $)$ en un tiempo $t ; R$ es la constante de los gases ideales $\left(\operatorname{atmLmol}{ }^{-1} \mathrm{~K}^{-1}\right)$ y $T$ es la temperatura del experimento $(\mathrm{K})$.

$$
L N\left(\frac{M_{U}}{M}\right)=K_{h} t
$$

Donde $L N$ es el logaritmo natural; $t$ tiempo (d), $M_{U}$ es la producción de metano al final de experimento $\left(\mathrm{molL}^{-1}\right) ; M$ es la producción remanente en el tiempo $(M=M u-M(t))$ y $K_{h}$ es la constate de tiempo de hidrólisis $\left(\mathrm{d}^{-1}\right)$.

La duración de la fase de latencia $(\lambda)$ fue determinada a partir de la función logística sugerida por Li et al. [17] utilizando la Ecuación 3.

$$
V_{C H_{4}}(t)=\frac{P_{\max }}{1+\exp \left[\frac{4 R_{\max }(\lambda-t)}{P_{\max }}+2\right]}
$$

Donde $\mathrm{VCH}_{4}(t)$ es la producción de metano en el tiempo $\left(\mathrm{mLCH}_{4} \mathrm{~h}^{-1}\right), P_{\max }$ es la máxima producción de metano $\left(\mathrm{mLCH}_{4}\right), R_{\text {máx }}^{\text {max }}$ la tasa máxima producción de metano $\left(\mathrm{mLCH}_{4} \mathrm{~h}^{-1}\right)$ y $\lambda$ es la fase de latencia $(\mathrm{h})$. La validación tanto del modelo cinético de primer orden como del ajuste de función logística, se hizo a partir del coeficiente de determinación $\left(R^{2}\right)$ y el cuadrado medio del error (CME) solamente para la función logística. El ajuste de los modelos 
matemáticos empleados se realizó usando la herramienta Excel del paquete Office 2007.

\section{Resultados y Análisis}

\section{Caracterización del sustrato e inóculos}

La Tabla 1 muestra los resultados de la caracterización fisicoquímica de los BOM. En general, los valores de $\mathrm{pH}$, Humedad, AT, ATB y AGV's se encuentran dentro del rango característico de residuos rápidamente acidificables [18]. El contenido de humedad es elevado y está asociado con la presencia de una mayor proporción de residuos vegetales y de frutas, los cuales se caracterizan por ser de fácil degradación, que pueden ser convertidos rápidamente en $A G V$ 's [14], incidiendo en los bajos valores de $\mathrm{pH}$, ausencia de $A B$ y elevada acidez como se observa en la Tabla 1. Otro factor que puede ser causante de los bajos valores de $\mathrm{pH}$ y ausencia de alcalinidad de los BOM, es su elevado contenido de carbohidratos fácilmente hidrolizables que favorecen la fermentación natural y por consiguiente la formación de AGV's [19]. Los valores de $\mathrm{DQO}_{\text {total }}, \mathrm{DBO}_{5}, \mathrm{UV}_{254}, \mathrm{SV}$ y COT muestran que los BOM presentan alto contenido materia orgánica biodegradable como lo reflejan las relaciones $\mathrm{DBO}_{5} / \mathrm{DQO}(0,9)$ y $\operatorname{SV} / \mathrm{ST}(0,84)$ lo que indica un alto potencial para la aplicación de un tratamiento anaerobio. Sin embargo, la relación $\mathrm{DQO}_{\text {filtrada }} / \mathrm{DQO}$ total fue 0,30 , mostrando que gran parte de ésta se encuentra en forma particulada lo que hace que el proceso de hidrólisis sea más prologando y que el éxito del mismo se deba a la variedad y diversidad de los consorcios microbianos presentes en el inóculo.

Las relaciones C/N y DQO:N:P fueron 33,6 y $1000: 9,3: 0,9$, respectivamente, las cuales se encuentran en el rango recomendado para la DA (20-35 y 1000:5:1) de acuerdo con Khalid et al. [20]. El valor obtenido permite proporcionar el nitrógeno y fósforo suficiente para el proceso, el cual es esencial para la síntesis de proteínas y es requerido principalmente como nutriente por los microorganismos en la DA [20]. Por otro lado, la concentración de nitrógeno amoniacal total no ionizado $\left(\mathrm{NH}_{3}\right)$ presente en los BOM no es inhibitoria, ya que predomina la forma ionizada la cual aporta capacidad buffer; sin embargo esta no es suficiente para reducir las propiedades ácidas del sustrato, pues se encuentra por debajo de la concentración recomendada (1100mgL-1) [21]. A

Tabla1. Caracterización fisicoquímica de los BOM.

\begin{tabular}{|c|c|c|}
\hline Parámetro & Promedio $\pm \sigma$ & Unidades \\
\hline Humedad $(n=4)$ & $86,72 \pm 3,65$ & $\%$ \\
\hline $\mathrm{pH}(\mathrm{n}=4)$ & $5,05 \pm 0,04$ & Unidades \\
\hline Alcalinidad Total $(A T)(n=4)$ & $4212,68 \pm 5,17$ & $\mathrm{mgCaCO}_{3} \mathrm{~L}^{-1}$ \\
\hline Alcalinidad Bicarbonática $(A B)(n=4)$ & 0 & $\mathrm{mgCaCO}_{3} \mathrm{~L}^{-1}$ \\
\hline Ácidos Grasos Volátiles (AGV's) (n=4) & $24611,44 \pm 12,66$ & $\mathrm{mgL}^{-1}$ \\
\hline Demanda Química de Oxígeno $\left(\mathrm{DQO}_{\text {Total }}\right)(\mathrm{n}=4)$ & $125812,31 \pm 479,08$ & $\mathrm{mgL}^{-1}$ \\
\hline Demanda Química de Oxígeno $\left(\mathrm{DQO}_{\text {Filtrada }}\right)(\mathrm{n}=4)$ & $38187,10 \pm 140,57$ & $\mathrm{mgL}^{-1}$ \\
\hline Demanda Biológica de Oxígeno $\left(\mathrm{DBO}_{5}\right)(\mathrm{n}=4)$ & $113346,60 \pm 495,63$ & $\mathrm{mgL}^{-1}$ \\
\hline Sólidos Totales $(\mathrm{ST})(\mathrm{n}=4)$ & $110740,46 \pm 242,09$ & $\mathrm{mgL}^{-1}$ \\
\hline Sólidos Volátiles (SV) $(n=4)$ & $93127,77 \pm 147,48$ & $\mathrm{mgL}^{-1}$ \\
\hline $\mathrm{UV}_{254}(\mathrm{n}=4)$ & $>3,30$ & $\mathrm{~cm}^{-1}$ \\
\hline Carbono Orgánico Total* $(\mathrm{COT})(\mathrm{n}=4)$ & $39850 \pm 12737,82$ & $\mathrm{mgKg}^{-1}$ \\
\hline Nitrógeno total $(N)^{*}(n=4)$ & $1186,25 \pm 200,74$ & $\mathrm{mgKg}^{-1}$ \\
\hline Nitrógeno total amoniacal (NAT) $(n=3)$ & $85,71 \pm 63,06$ & $\mathrm{mgL}^{-1}$ \\
\hline Nitrógeno amoniacal no ionizado $\left(\mathrm{NH}_{3}\right)(\mathrm{n}=3)$ & $0,01 \pm 0,006$ & $\mathrm{mgL}^{-1}$ \\
\hline Nitrógeno amoniacal ionizado $\left(\mathrm{NH}_{4}^{+}\right)(\mathrm{n}=3)$ & $85,70 \pm 63,06$ & $\mathrm{mgL}^{-1}$ \\
\hline Fósforo Total $(P-T o t a l)(n=3)$ & $118,16 \pm 34,18$ & $\mathrm{mgkg}^{-1}$ \\
\hline
\end{tabular}

*Base húmeda. 
rev.ion. 2016;29(1):37-46. Bucaramanga (Colombia).

Tabla 2. Caracterización fisicoquímica de los inóculos empleados.

\begin{tabular}{|c|c|c|c|c|}
\hline Parámetros & Inóculo A & Inóculo B & Inóculo C & Unidades \\
\hline $\mathrm{pH}(\mathrm{n}=4)$ & $7,42 \pm 0,16$ & $7,18 \pm 0,20$ & $7,97 \pm 0,04$ & Unidades \\
\hline AT $(n=4)$ & $2461,38 \pm 378,17$ & $2620,28 \pm 359,43$ & $3568,20 \pm 371,52$ & $\mathrm{mgCaCO}_{3} \mathrm{~L}^{-1}$ \\
\hline$A B(n=4)$ & $1277,01 \pm 279,89$ & $977,95 \pm 135,56$ & $2525,28 \pm 407,84$ & $\mathrm{mgCaCO}_{3} \mathrm{~L}^{-1}$ \\
\hline Relación AB/AT & 0,5 & 0,4 & 0,7 & - \\
\hline AGV $(n=4)$ & $873,00 \pm 104,06$ & $576,00 \pm 9,66$ & $1071,00 \pm 31,74$ & $\mathrm{mgL}^{-1}$ \\
\hline AGV /AT & 0,35 & 0,22 & 0,30 & - \\
\hline $\mathrm{ST}(\mathrm{n}=4)$ & $53964,00 \pm 1603,72$ & $86416,25 \pm 2837,26$ & $35263,25 \pm 3534,83$ & $\mathrm{mgL}^{-1}$ \\
\hline SV $(n=4)$ & $36783,75 \pm 2116,02$ & $42178,75 \pm 3448,90$ & $15826,25 \pm 1989,09$ & $\mathrm{mgL}^{-1}$ \\
\hline SVIST & 0,68 & 0,49 & 0,36 & - \\
\hline Sedimentabilidad & 0,10 & 0,10 & 0,10 & $\mathrm{mh}^{-1}$ \\
\hline AME $(A G V)^{*}$ & 0,01 & 0,01 & 0,00 & $\mathrm{gDQO}_{\mathrm{CH} 4} \mathrm{SV}^{-1} \mathrm{~d}^{-1}$ \\
\hline
\end{tabular}

*Ácido acético (73\%); ácido propiónico (23\%); ácido butírico (4\%).

continuación la Tabla 2 muestra la caracterización fisicoquímica de cada uno de los inóculos empleados en los ensayos.

Se puede apreciar que los valores de $\mathrm{pH}$ de los tres inóculos evaluados coinciden con los encontrados en la literatura para lodos anaerobios procedentes de PTAR's municipales [22,23]. La alcalinidad de los inóculos se encuentra en el rango recomendado para la DA $\left(>2000 \mathrm{mgCaCO}_{3} \mathrm{~L}^{-1}\right)$ según lo recomendado por Lorenzo et al. [24].

Las relaciones AB/AT (también conocido como índice $\alpha$ ) indican que el inóculo $C$ presentó la mayor capacidad buffer, ya que de acuerdo con autores como Cajigas et al. [25], esta relación debe ser superior a 0,5 durante el arranque y alcanzar condiciones estables en el sistema con valores de 0,7 , lo que puede estar asociado a las características del agua residual que por estar mezcladas con aguas residuales industriales, puede presentar mayores concentraciones de fosfatos que aportan alcalinidad al medio [26]. Del mismo modo, relación AGVIAT presentó valores inferiores a 0,4 [27].

Aunque la relación SVIST es usada como un indicador indirecto de la biomasa activa del lodo[28] y además se espera que la zona más activa esté localizada en el tramo de reactor en que existe mayor contacto con el sustrato (lugar donde se tomaron las muestras de lodo), en los Inóculos B y C se obtuvieron valores bajos [28], lo que puede estar asociado a problemas o deficiencias operacionales como rutinas de purga de lodos o problemas hidrodinámicos que pueden afectar la distribución del lodo dentro de los reactores [29], lo que altera el equilibrio de los grupos sintróficos en los inóculos.
El valor obtenido para la sedimentabilidad de los inóculos indica que éstos son dispersos, pues su velocidad de sedimentación se encuentra entre 0,05 y $0,2 \mathrm{mh}^{-1}$. De acuerdo con Jiménez et al. [30], en este tipo de inóculos no hay agregados de partículas, tienen pobres propiedades de sedimentación y baja actividad metanogénica. Esto se debe posiblemente a que las AR que tratan estos reactores son muy diluidas o con baja concentración de DQO, lo que no permite la formación de gránulos como en caso de AR con alta concentración orgánica (DQO>3000 $\mathrm{mgL}^{-1}$ ), las cuales permiten que se obtenga una mayor actividad metabólica [31], esto se relaciona con lo mencionado por Quintero [32], quien encontró que los lodos anaerobios de aguas residuales de este tipo presentan AME inferiores a 0,01gDQOSV-1 $\mathrm{d}^{-1}$. Por lo anterior, se puede deducir que las características de los lodos de plantas de tratamiento de agua residuales -PTAR, están influenciadas por aspectos relacionados con la operación y mantenimiento de las diferentes unidades que las componen, lo que incide significativamente sobre la calidad microbiana de la biomasa activa presente en éstos, siendo recomendable realizar perfiles de lodos en los digestores para identificar las zonas donde se concentra la fracción más activa de la biomasa, que pueda ser considera adecuada para su uso como inóculo en procesos anaerobios.

Influencia del tipo de inóculo y la relación Sustrato-Inóculo

La Figura 2 presenta los valores de producción de metano para cada inóculo y su relación $\mathrm{S} / \mathrm{l}$. De acuerdo a los resultados del ANOVA $(p>0,05)$ no 
existen diferencias estadísticas significativas entre los inóculos en cuanto a la producción de metano; sin embargo, se encontraron diferencias entre las relaciones $\mathrm{S} / \mathrm{l}$ evaluadas, evidenciándose que los

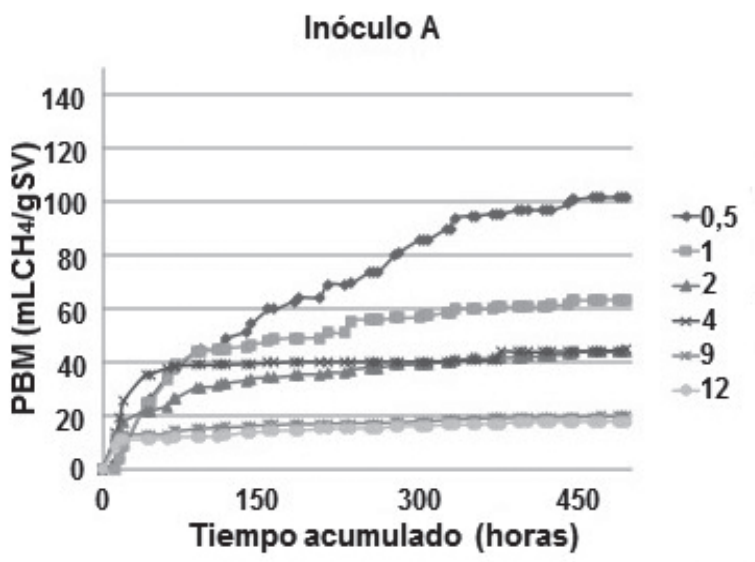

mayores PBM se obtuvieron con relaciones S/I inferiores a 1, lo cual corrobora lo expresado por Pabón et al. [11] quienes expresan que cuando se incrementa la carga orgánica en el proceso de DA

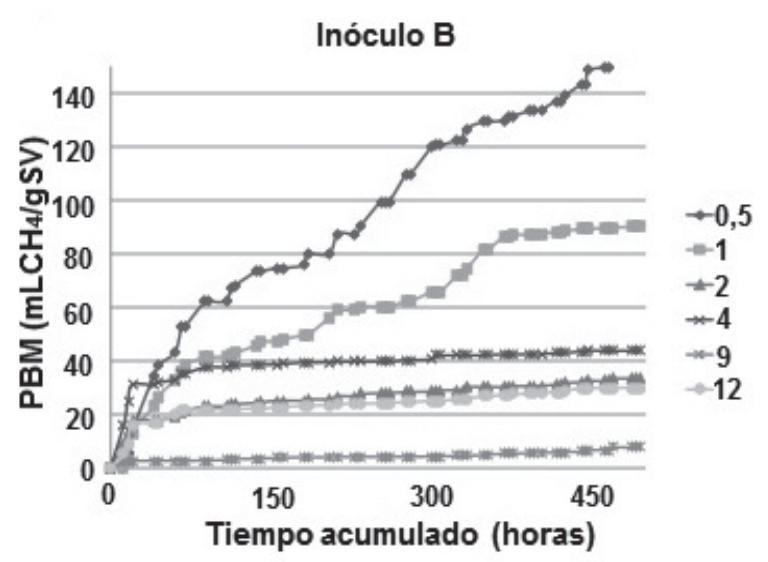

Inóculo C

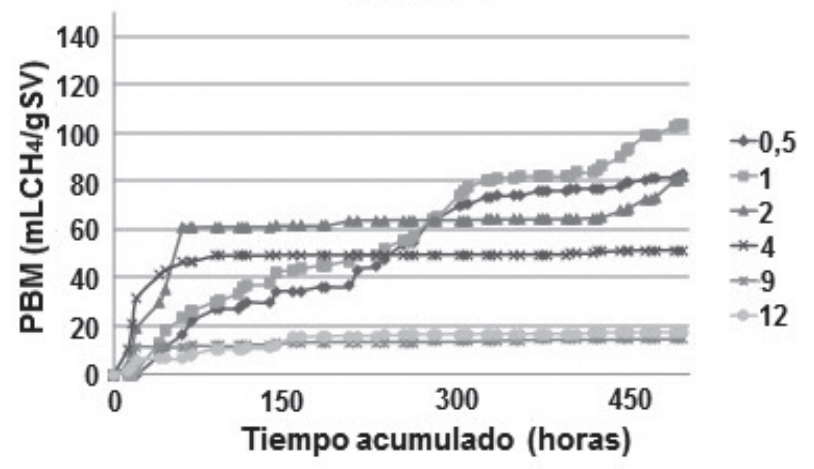

Figura 2. PBM para cada inóculo y sus respectivas relaciones S/I.

de los BOM, se presentan efectos inhibitorios por la acumulación de sustancias tóxicas, principalmente ácidos grasos volátiles.

Se resalta también que el Inóculo $C$ presentó una mayor producción en la relación $\mathrm{S} / \mathrm{I}$ de 2 respecto a los otros, lo que puede ser atribuida a su mayor capacidad amortiguadora asociada con una mayor concentración de $A B\left(2525 \mathrm{mgL}^{-1}\right)$ y una mayor relación $A B / A T$ o índice $\alpha$, que pudo neutralizar el posible incremento de AGV's y por ende, evitar la inhibición del proceso. Lo anterior contrasta con los resultados reportados por Elbeshbishy et al. [33] quienes encontraron producciones de metano superiores a $660 \mathrm{~mL} \mathrm{gSV}^{-1}{ }_{\text {sustrato }}$.En éste estudio se utilizó un inóculo de PTAR que tratan aguas residuales de sistemas de alcantarillado separado; por consiguiente, la biomasa presenta un mecanismo enzimático capaz de transformar mayores concentraciones de materia orgánica a diferencia de los inóculos empleados en esta investigación. Con relación al efecto sobre la etapa de hidrólisis, la Tabla 3 muestra los resultados de $K_{h}$ y la fase de latencia $(\lambda)$ para cada relación $\mathrm{S} / \mathrm{I}$ evaluada.

Se observa que a medida que se incrementa la relación S/l, se reduce la tasa de hidrólisis $\left(K_{h}\right)$ para cada uno de los inóculos. La fase de latencia indica el periodo en el cual los microorganismos se adaptan al sustrato [34]; en este estudio estuvo entre 0,7 y 30,7 días para todos los inóculos, siendo los períodos más cortos y los de las mejores $K_{h}$ con correlaciones fuertes y CME bajo, los asociados al Inóculo C, lo cual puede atribuirse a la mayor capacidad buffer que presentó.

Por otro lado, se resalta que los mejores resultados de ajuste al modelo de primer orden y función logística se presentaron en las relaciones inferiores a $1\left(R^{2}>0,9\right.$ y $\left.C M E<3\right)$. Aunque en algunos casos se presentaron buenos ajustes en el modelo de función logística para relaciones mayores a 2, al observar $K_{h}$ se aprecia que presentan un coeficiente de determinación débil $\left(R^{2}<0,5\right)$, esto 
indica que efectivamente la fase de hidrólisis es la etapa limitante en la DA de BOM. Esto se asemeja a lo reportado por Yoon et al. [35], quienes aseveran que a medida se incrementa la relación $S / l$ la fase de latencia se prolonga, asociada principalmente al incremento de sustancias inhibitorias como los AGV's. De igual manera se pueden presentar fases de latencia negativas como lo afirma Blanco [36], quien durante sus investigaciones de DA encontró fases de latencia prolongadas y negativas
(22 y -77,7días, respectivamente) atribuyendo esto a las altas concentraciones de AGV's relacionadas a las cargas empleadas. Raposo et al. [37], también afirman que este suceso está atribuido al aumento de la carga orgánica, ya que se propician fenómenos de inhibición, los cuales a su vez reducen el crecimiento de la biomasa activa, puesto que durante sus investigaciones encontraron que inóculos con baja actividad microbiana son más propensos a una fase de

Tabla 3. Valores de la constante de hidrólisis y la fase de latencia.

\begin{tabular}{|c|c|c|c|c|c|c|c|c|}
\hline & \multirow{2}{*}{$S / l$} & \multicolumn{2}{|c|}{ Modelo primer orden } & \multicolumn{5}{|c|}{ Función Logística } \\
\hline \multirow{7}{*}{ Inóculo A } & & $K_{h}\left(\mathrm{~d}^{-1}\right)$ & $\mathbf{R}^{2}$ & $\lambda(\mathrm{d})$ & $P_{\max }(\mathrm{mL})$ & $R_{\max }\left(\mathrm{mLh}^{-1}\right)$ & $\mathbf{R}^{2}$ & CME \\
\hline & 0,5 & 0,19 & 0,91 & 6 & 15,32 & 0,049 & 0,97 & 0,694 \\
\hline & 1 & 0,20 & 0,9 & 2,7 & 17,59 & 0,128 & 0,92 & 2,084 \\
\hline & 2 & 0,18 & 0,69 & 2 & 25,45 & 0,109 & 0,92 & 2,421 \\
\hline & 4 & 0,20 & 0,80 & 0,7 & 49,33 & 1,467 & 0,92 & 7,204 \\
\hline & 9 & 0,19 & 0,83 & $-0,76^{*}$ & 51,47 & 0,165 & 0,77 & 17,769 \\
\hline & 12 & 0,21 & 0,80 & 0,63 & 64,33 & 0,151 & 0,84 & 22,303 \\
\hline \multirow{7}{*}{ Inóculo B } & $\mathrm{S} / \mathrm{l}$ & $K_{h}\left(\mathrm{~d}^{-1}\right)$ & $\mathbf{R}^{2}$ & $\lambda(\mathrm{d})$ & $P_{\max }(\mathrm{mL})$ & $R_{\max }\left(\mathrm{mLh}^{-1}\right)$ & $\mathbf{R}^{2}$ & CME \\
\hline & 0,5 & 0,17 & 0,81 & 7,5 & 23,67 & 0,057 & 0,96 & 1,751 \\
\hline & 1 & 0,21 & 0,89 & 7,3 & 29,38 & 0,065 & 0,94 & 3,704 \\
\hline & 2 & 0,15 & 0,43 & 1,5 & 18,71 & 0,074 & 0,87 & 1,982 \\
\hline & 4 & 0,19 & 0,84 & 0,8 & 49,49 & 0,595 & 0,84 & 12,511 \\
\hline & 9 & 0,07 & 0,65 & 30,7 & 60,24 & 0,047 & 0,91 & 1,722 \\
\hline & 12 & 0,24 & 0,42 & 1,4 & 96,71 & 0,540 & 0,80 & 91,845 \\
\hline \multirow{7}{*}{ Inóculo C } & $S / I$ & $K_{h}\left(\mathrm{~d}^{-1}\right)$ & $\mathbf{R}^{2}$ & $\lambda(\mathrm{d})$ & $P_{\max }(\mathrm{mL})$ & $R_{\max }\left(\mathrm{mLh}^{-1}\right)$ & $\mathbf{R}^{2}$ & CME \\
\hline & 0,5 & 0,20 & 0,85 & 8,4 & 21,05 & 0,064 & 0,98 & 1,017 \\
\hline & 1 & 0,15 & 0,71 & 9,3 & 32,01 & 0,075 & 0,97 & 2,975 \\
\hline & 2 & 0,10 & 0,59 & 1,6 & 39,27 & 0,826 & 0,92 & 8,732 \\
\hline & 4 & 0,18 & 0,48 & 0,8 & 59,54 & 1,726 & 0,97 & 4,478 \\
\hline & 9 & 0,21 & 0,42 & 0,67 & 36,05 & 3,512 & 0,85 & 8,083 \\
\hline & 12 & 0,18 & 0,45 & 3,3 & 61,16 & 0,327 & 0,97 & 8,889 \\
\hline
\end{tabular}

$\lambda$ : Fase de latencia; N.D: No determinado * Sin explicación biológica

decaimiento de la biomasa rápida por el aumento en la concentración de sustrato, lo que a su vez se ve reflejado en una baja producción de metano.

\section{Conclusiones}

La relación Sustrato-Inóculo influye sobre la digestión anaerobia de los biorresiduos, siendo la relación de 1 la que en general presentó el mejor desempeño; adicionalmente, el comportamiento de las tasas de hidrólisis y fases de latencia, validaron que la hidrólisis es la etapa limitante de este proceso biológico.

Un aspecto que se mostró fundamental en el buen desempeño de los inóculos, fue su capacidad buffer, reflejada en la relación AB/AT o Índice $\alpha$, siendo más eficiente el inóculo que presentó el mayor valor, ya que esta característica minimiza la ocurrencia de procesos de acidificación por la acumulación de los AGV's.

\section{Agradecimientos}

Los autores agradecen a la Universidad del Valle por la financiación del proyecto de investigación "Aprovechamiento de los Subproductos a partir de la Digestión Biológica de Residuos Sólidos de Origen Municipal-Cl 2811" y a COLCIENCIAS por la financiación del estudiante Brayan A. 
Parra Orobio como becario del doctorado nacional Convocatoria 617 - 2013 -Segundo Corte.

\section{Referencias bibliográficas}

[1] Oviedo Ocaña ER, Torres LP, Marmolejo Rebellon LF, Hoyos LV, Gonzales S, Barrena $\mathrm{R}$, et al. Stability and maturity of biowaste composts derived by small municipalities: Correlation among physical, chemical and biological indices. Waste Management. 2015;44(1):63-71

[2] Andrade IM, Buitrón MG . Influencia del origen del inóculo en la prueba de biodegradabilidad anaerobia. En: XIII Congreso Nacional de la Federación Mexicana de Ingeniería Sanitaria y Ciencias Ambientales, Guanajuato. 2002.

[3] Raposo F, De La Rubia MA, FernándezCegrí V, Borja R. Anaerobic digestion of solid organic substrates in batch mode: An overview relating to methane yields and experimental procedures. Renew. Sustainable Energy Rev. 2012;16(1):861-77.

[4] Angelidaki I, Alves M, Bolzonella D, Borzacconi L, Campos JL, Guwy AJ, et al. Defining the biomethane potential (BMP) of solid organic wastes and energy crops: A proposed protocol for batch assays. Water Sci. Technol. 2009;59(5):927-34.

[5] Torres Lozada P, Rodríguez Victoria JA, Cajigas Cerón AA, Pérez Vidal A. La actividad metanogénica como herramienta para optimización del proces o anaerobio en el tratam iento de aguas residuales fácilmente acidificables. En: XXVIII Congreso Interamericano de Ingeniería Sanitaria y Ambiental, AIDIS, Cancún, México. 2002.

[6] De Vrieze J, Raport L, Willems B, Verbrugge $\mathrm{S}$, Volcke E, Meers E, et al. Inoculum selection influences the biochemical methane potential of agro-industrial substrates. Microb. Biotechnol. 2015;8(5):776-86.

[7] ICONTEC. Norma Técnica Colombiana 5167. Productos para la Industria Agrícola, Productos Orgánicos Usados como Abonos o Fertilizantes y Enmiendas de Suelo. 2004. p. 32.

[8] APHA, Standard methods for examination of water and wastewater.A.W.W.A.a.W.E. Federation. Washington D.C., E.E. U.U. 2005.

[9] Torres Lozada P, Pérez Vidal A. Actividad Metanogénica Específica: Una herramienta de control y optimización de sistemas de tratamiento anaerobio de aguas residuales. Revista EIDENAR. 2010;9:5-14.

[10] Sharma SK, Mishra IM, Sharma MP, Saini JS. Effect of particle size on biogas generation from biomass residues. Biomass.1988;17(4):251-63.

[11] Pabón Pereira CP, Castañares G, van Lier JB. An OxiTop $\AA$ protocol for screening plant material for its biochemical methane potential (BMP). Water Sci. Technol. 2012;66(7):141623.

[12]Aquino SF. Influência das condições de incubação no teste de atividade metanogênica específica (AME) de lodos anaeróbios. Dissertação de Mestrado. Belo Horizonte, Brasil. Escola de Engenharia, Universidade Federal de Minas Gerais. 2007.

[13] Siefers AM. A novel and cost-effective hydrogen sulfide removal technology using tire derived rubber particles. Thesis Master. lowa, E.E.U.U. lowa State University. 2010

[14] Parra Orobio BA, Torres Lozada P, Marmolejo Rebellón LF, Cárdenes Cleves LM, Vásquez Franco C, Torres López WA, Ordoñez Andrade JA. Efecto de la relación sustrato-inóculo sobre el potencial bioquímico de metano de biorresiduos de origen municipal. Ingeniería Investigación y Tecnología. 2015;16(4):51526.

[15] Field J. Arranque y operación de sistemas de flujo ascendente con manto de lodo UASB. Universidad del Valle, CVC y Universidad Agrícola de Wageningen. 1987.

[16] Liew LN, Shi J, Li Y. Methane production from solid-state anaerobic digestion of lignocellulosic biomass. Biomass Bioenergy. 2012;46:125-32.

[17] Li L, Kong X, Yang F, Li D, Yuan Z, Sun Y. Biogas production potential and kinetics of microwave and conventional thermal pretreatment of grass. Appl Biochem Biotechnol. 2012:166(5):1183-91.

[18] Juanga JP. Optimizing dry anaerobic digestion of organic fraction of municipal solid waste (Thesis Master). Bangkok, Thailand: School of Environment, Resources and Development, Asian Institute of Technology; 2005.

[19] Sundberg C, Franke-Whittle IH, Kauppi S, Yu D, Romantschuk $M$, Insam $H$, Jönsson $\mathrm{H}$. Characterisation of source-separated household waste intended for composting. Bioresour. Technol. 2011;102(3):2859-67.

[20] Khalid A, Muhammad A, Muzammil A, 
Mahmood T, Dawson L. The anaerobic digestion of solid organic waste. Waste Manage. 2011;31(8):1737-44.

[21] Parawira W, Murto M, Zvauya R, Mattiasson B. Anaerobic batch digestion of solid potato waste alone and in combination with sugar beet leaves. Renew. Energy. 2004;29(11):1811-23.

[22] Bolzonella D, Battistoni P, Susini C, Cecchi $F$. Anaerobic codigestion of waste activated sludge and OFMSW: The experiences of Viareggio and Treviso plants (Italy). Water Sci. Technol. 2006;53(8):203-11.

[23] Fernández M, Abalos $A$, Crombet $S$, Caballero $\mathrm{H}$. Ensayos de biodegradabilidad anaerobia de aguas residuales generadas en una planta refinadora de aceite de soja. Interciencia. 2010;35(8):600-4.

[24] Lorenzo Acosta Y, Obaya Abreu MC. La digestión anaerobia. Aspectos teóricos. Parte I, ICIDCA. Sobre los Derivados de la Caña de Azúcar. 2005;39(1):35-48.

[25] Cajigas Ceron AA, Pérez Vidal A, Torres Lozada P. Importancia del $\mathrm{pH}$ y la alcalinidad en el tratamiento anaerobio de las aguas residuales del proceso de extracción de almidón de yuca. Scientia et Technica. 2005;1(27):243-8.

[26] Marín A, Osés M. Operación y mantenimiento de Plantas de Tratamiento deAguas Residuales con el proceso de lodos activados. Comision Estatal Del Aguas De Jalisco. Disponible en: http://www.ceajalisco.gob.mx/publicaciones/ pdf/plantas_tratam_tomo1.pdf. Acceso 25 de octubre de 2015.

[27] Callaghan FJ, Wase DAJ, Thayanity K, Forster CF. Continuous co-digestion of cattle slurry with fruit and vegetable wastes and chicken manure. Biomass Bioenergy. 2002;22(1):71-7.

[28] Torres Lozada P, Cardoso A, Rojas O. Mejoramiento de la calidad de lodos anaerobios. Ingeniería y Competitividad. 2004;5(2):23-31.

[29] Suárez Marmolejo CL. Tratamiento de aguas residuales municipales en el valle del cauca
(Tesis Pregrado). Cali, Colombia: Universidad del Valle; 2011.

[30] Jiménez EL, Mojica ML. Estudio de factibilidad de un reactor anaerobio de flujo a pistón a escala de laboratorio, en el tratamiento de las aguas residuales domésticas del municipio de Tunja a una temperatura promedio de $14^{\circ} \mathrm{C}$. Tecnogestión. 2005;11:13-8.

[31]Chávez M, Mejías D, Masy RM, Escorihuela A, Chacín E, Fernández N. Evaluación de la biomasa en el lodo granular anaerobio en reactores por carga. Multiciencias. 2003;3(2):1-9.

[32] Quintero M. Estudio de consorcios microbioanos para la producción de biogás a partir de residuos de fique. (Tesis Maestría). Bucaramanga, Colombia: Universidad Industrial de Santander; 2011.

[33] Elbeshbishy E, Nakhla G, Hafez H. Biochemical methane potential (BMP) of food waste and primary sludge: Influence of inoculum preincubation and inoculum source. Bioresour. Technol. 2012;110:18-25.

[34]Donoso-Bravo A, Pérez-Elvira SI, FdzPolanco F. Application of simplified models for anaerobic biodegradability tests. Evaluation of pre-treatment processes. Chem. Eng. J. 2010;160(2):607-14.

[35] Yoon YM, Kim SH, Shin KS, Kim CH. Effects of substrate to inoculum ratio on the biochemical methane potential of piggery slaughterhouse wastes. Asian Austral J Anim. 2014;27(4):600-7.

[36]Blanco CD. Tratamiento biológico aerobioanaerobio-aerobio de residuos ganaderos para la obtención de biogás y compost. (Tesis Doctoral). León, España: Universidad de Leon; 2011.

[37] Raposo F, Banks CJ, Siegert I, Heaven S, Borja R. Influence of inoculum to substrate ratio on the biochemical methane potential of maize in batch tests. Process Biochem. 2006;41(6):1444-50. 